Corps et culture

Numéro 6/7 | 2004

Métissages

\title{
Corps et cultures métisses, afro-rythmes et danses
} urbaines

\section{Nancy Midol}

\section{(2) OpenEdition}

1 Journals

Édition électronique

URL : http://journals.openedition.org/corpsetculture/811

DOI : 10.4000/corpsetculture.811

ISSN : $1777-5337$

Éditeur

Association Corps et Culture

Édition imprimée

Date de publication : 1 janvier 2004

ISSN : 1268-5631

Référence électronique

Nancy Midol, «Corps et cultures métisses, afro-rythmes et danses urbaines », Corps et culture [En

ligne], Numéro 6/7 | 2004, mis en ligne le 11 octobre 2007, consulté le 08 septembre 2020. URL:

http://journals.openedition.org/corpsetculture/811 ; DOI : https://doi.org/10.4000/corpsetculture.811

Ce document a été généré automatiquement le 8 septembre 2020

(c) tous droits réservés 


\title{
Corps et cultures métisses, afro- rythmes et danses urbaines
}

\author{
Nancy Midol
}

1 La question que Serge Gruzinski pose dans son ouvrage La Pensée métisse (1999) revient à savoir comment des cultures se mélangent, dans quelles circonstances et selon quelles modalités. Serge Gruzinski étudia comment les indigènes mexicains géminèrent leur symbolique culturelle dans des œuvres architecturales, des fresques et autres objets destinés à célébrer le culte chrétien des nouveaux colons espagnols au Mexique. Il étudia donc le métissage spirituel et artistique à travers les vestiges architecturaux. On sait que ce phénomène de mélange se produisit aussi chez les esclaves africains transportés au Brésil et en Amérique, et comment les cathédrales érigées durant le temps colonial sont bâties sur des figurines de divinités africaines, enterrées dans les fondations. Ainsi la dévotion ostentatoire des fidèles noirs permettait-elle de célébrer le Christ en même temps que leurs divinités comme Ogun, Oshun ou Yémanga.

2 Ainsi la mise en contact de plusieurs cultures comme ce fut le cas en Amérique latine, engage un phénomène de métissage à la créativité florissante. François Laplantine parle même de la capacité du métissage à fabriquer des "identités plurielles », le métissage consistant alors à «la différenciation extrême de soi-même pouvant aller jusqu'à la présence de l'autre en soi, comme dans les cultes de possession, est souvent plus culturel que proprement ethnique...» (1997: 27). C'est notamment dans l'Umbanda, la religion nationale des brésiliens d'après François Laplantine... «que culmine ce mouvement d'irruption des autres en nous $»^{1}$.

3 De ces deux exemples on tirera l'idée que la mise en contact de deux cultures peut engager un phénomène de métissage dont on cherchera les niveaux de créativité. Présent dans les expressions symboliques et artistiques comme l'a montré Gruzinski, le métissage vient-il jusqu'au niveau corporel modifier, non seulement des techniques artisanales mais aussi des techniques du corps ? Cette question ne peut être posée que pour la période contemporaine qui permet le recours à une méthodologie de l'observation des mises en action du corps. Il faut aussi circonscrire cette question, et c'est à propos des expressions artistiques qui engagent le corps dans une motricité de 
danse que l'observation sur des processus de métissage est envisagée. D'où l'idée de réfléchir au métissage au niveau du corps, des techniques du corps, pour une anthropologie de l'actuel.

\section{La rencontre avec l'étranger : des arts métis}

4 Le métissage est certes à la mode aujourd'hui, et pourtant ce n'est pas un phénomène nouveau. Au-delà des croisements de races blanche, jaune et noire, il procède d'une sorte d'alchimie ou plus prosaïquement d'un bricolage auquel personne n'échappe dans son existence quand il faut composer avec la culture des familles paternelle et maternelle, mais aussi avec ces cultures multiples que véhiculent les institutions scolaire, médiatique, de loisir, ou les coutumes de ses voisins dans son quartier. Il n'y a donc pas besoin d'être un enfant né de parents de races différentes pour cela. Mais bien sûr, composer avec des éléments hétérogènes et parfois contradictoires se fait à des degrés divers, selon les situations d'immersion sociétale et d'imprégnation culturelle, participant à des constructions identitaires toujours en devenir.

5 Il faut remarquer que les arts occidentaux sont interpellés par la force expressive des cultures exotiques. Mais cela n'est pas nouveau, la Grèce Antique ne fit-elle pas entrer Dionysos l'Asiatique, l'oriental dans son panthéon? Plus récemment, depuis les grands mouvements de colonisation et de décolonisation, "l'art nègre " a imprégné la modernité occidentale. Pablo Picasso, Georges Braque ont puisé dans l'esthétique africaine de quoi revitaliser la créativité moderne. Antonin Artaud voulut le théâtre avec la corporéité du théâtre balinais. A un niveau plus populaire, les capitales occidentales s'étourdirent avec le Jazz, l'art supposé nègre des revues de music-hall, comme celle de Joséphine Baker par exemple.

Il en fut de même pour la danse artistique qui s'est renouvelée au début du xxe siècle en visitant les danses de l'Orient, de l'Inde à l'Egypte, dans l'école réputée du Denishawn qui fut la pépinière de tous les grands chorégraphes de la modernité américaine. Martha Graham issue de cette école explora les danses amérindiennes. Mais le plus grand chorégraphe du métissage à la période moderne est sans conteste Alvin Haley qui a laissé derrière lui une œuvre d'art métis, introduisant l'âme africaine dans la danse américaine.

7 Le métissage est plus évident à des époques qu'à d'autres et dans des aires géographiques particulières selon les méandres de l'histoire des peuples. Le métissage est toujours le fruit d'une rencontre avec l'étranger, et c'est pourquoi les grandes invasions et les grands empires procèdent aux métissages ethniques, symboliques, techniques et spirituels de façon créative. Aujourd'hui dans le domaine des arts corporels et musicaux nous mesurons à quel point les grandes concentrations esclavagistes et coloniales ont produit des expressions métisses qui n'en finissent pas de revenir en boomerang, alimentant des expressions symboliques et stylistiques en perpétuel renouvellement. Le "retour de l'Afrique » en Occident n'en finit pas de se déployer dans un foisonnement de techniques artistiques hétérogènes. 


\section{"Métis », métissage et pensée moderne}

8 Le métissage s'impose pour qualifier la créativité de certaines expressions artistiques comme celles de la danse Jazz (Midol N., Pissard H.,1984) ou encore la break dance du hip hop (Midol N., 1995, 2000) et aujourd'hui de la danse contemporaine. Mais depuis une dizaine d'années, le métissage culturel tient l'avant-scène des cultures populaires urbaines et alternatives. Notamment dans les théâtres d'avant-garde de banlieues comme le théâtre Jean Vilar de Suresnes, le festival « Suresnes-cités-danse » qui ouvre ses portes depuis 10 ans à d'autres formes de danses, ou encore comme les « Rencontres urbaines » au Parc de la Villette à Paris qui, depuis 1996, font se rencontrer et dialoguer des artistes venant d'horizons divers, ou encore le festival de la danse à Lyon qui avait mis à l'honneur le métissage culturel dès 1988 en présentant la polyculture brésilienne sur les scènes théâtrales et dans les rues bruyantes quand les troupes de danseurs et de musiciens défilèrent aux rythmes de la samba et de la salsa entraînant le Lyonnais, de nature réservé, dans les délices d'une déambulation sensuelle. Mais le métissage n'est pas l'apanage des $\mathrm{xx}^{\mathrm{e}}$ et $\mathrm{xxI}^{\mathrm{e}}$ siècles. C'est lui qui a fait la célébrité du quattrocento par exemple, puis de la Renaissance.

9 C'est pourquoi il est surprenant que le concept de métissage culturel soit absent des dictionnaires, comme des encyclopédies. Pour le Robert du XIX ${ }^{e}$ siècle, il apparait fin XIII ${ }^{\mathrm{e}}$ siècle signifiant mélange ou mixtus, ce qui est fait à moitié avec une chose et à moitié avec une autre, qui est mélangé. Le terme est utilisé pour la technique du tissage : un tissu est métis quand la chaîne est par exemple en coton alors que la trame est en lin. Plus tard on parlera du métissage pour un croisement de races entre animaux ou humains. Mais ce qui est surprenant c'est combien peu est dit sur ces mots si beaux « métis, métissage, métisser ", comme si l'on avait à faire à de l'inconvenant, du dérangeant, mots avec lesquels il faut montrer une certaine réserve. L'encyclopédie de Diderot et d'Alembert consultée au mot « métis » fait référence aux dieux grecs :

«Les anciens mytholofes en ont fait une deeffe dont les lumières étoient fupérieures à celles des dieux même. Jupiter l'époufa, c'eft à dire, felon Appollodore, qu'il fit paraître beaucoup de prudence dans toutes ses conduites » (p. 756).

10 L'intérêt de cette Mètis n'avait pourtant pas échappé aux historiens Detienne et Vernant, qui en 1974 ont écrit : Les Ruses de l'intelligence, la mètis des grecs, pour parler d'une époque de grands chambardements entre la période théogonique (Chaos, Gaïa, Eros, Ouranos, Chronos) et le panthéisme qui aboutit après plusieurs revirements de situations au règne stabilisé de Zeus. Or la Mètis apparaît bien dans ces moments de désordre, c'est là qu'on a besoin de ses qualités et de son génie, de sa créativité rusée et raisonnable quand on est en danger de perdre la vie ou la face. Dans ce délicieux livre les auteurs excellent dans une démarche scientifique dont la complexité ne permet aucune réduction : ils passent du mythe notamment raconté par Homère et Hésiode à ce qui construit une logique mentale et une symbolique opérante dans le milieu humain et animal et jusque dans les figures du « cercle » et du " lien », et dans les techniques de chasse et de pêche, de la nasse au tissage, de la chaîne au piège. Ainsi traversent-ils

"l'univers culturel des Grecs dans toute son étendue, depuis ses plus anciennes

traditions techniques jusqu'à l'organisation de son panthéon » (1974:8).

11 Revenons de façon lapidaire sur l'origine du monde chez les Grecs. Pour les Grecs antiques, la terre naît d'une béance, d'un chaos où tout est confusion, obscurité, sans 
fond et sans direction. Gaïa la terre, née après Chaos est toute inverse : nette, ferme, stable, limitée. Elle est le plancher du monde et mère universelle, puis naît Eros, cette force de l'univers permet à la terre d'enfanter Ouranos, le Ciel. Or Ouranos "vautré » sur la terre l'épouse de toutes parts :

«Ouranos primordial n’a pas d'autre activité que sexuelle. Couvrir Gaïa sans cesse, autant qu'il le peut... Cette pauvre mère se trouve alors grosse de toute une série d'enfants qui ne peuvent pas sortir de son giron... car le ciel ne se dégage jamais de la terre » (Vernant J.-P., 1999 : 19-20).

C'est alors qu'un des enfants, Chronos, accepte de libérer sa mère en émasculant son père, de l'intérieur du ventre de Gaïa :

«Ouranos, au moment où il est châtré pousse un hurlement de douleur et s'éloigne vivement de Gaïa pour se fixer tout en haut du monde » (ibid., 1999 : 22).

Permettant à sa mère d'enfanter, Chronos participe à la séparation du principe mâle et du principe femelle, à « la nécessaire complémentarité entre les puissances du conflit et les puissances d'amour » (Detienne M., Vernant J.-P., 1974: 67), à la flèche du temps et préside au déroulement des cycles des vies diversifiées. La multiplicité peut apparaitre, et les affres du pouvoir avec elle. Deuxième temps : Chronos, craignant à son tour la révolte de ses fils, avale ses enfants, jusqu'au leurre tendu par sa femme Rhéa qui substitue une pierre à Zeus et sauve l'enfant. Mètis, première épouse de Zeus utilisera son intelligence rusée, sa vigilance toujours aux aguets, sa prudence et son génie pour chasser Chronos du trône au profit de Zeus. Loi du talion que Zeus réussit à stopper en avalant Mètis quand il apprend qu'elle enfantera un fils qui le détrônera à son tour. Avalant Mètis il incorpore cette fameuse intelligence de la ruse et du stratagème et rompt avec la loi du Talion. (ibid.,1974: 67). C'est donc avec la Mètis que Zeus peut introduire dans le royaume des cieux, le troisième temps, le temps du politique. Il prendra chez elle sa capacité à user de la ruse et non de la force. Il saurait exceller dans les terrains mouvants, incertains, les situations ambiguës, utilisant la capacité de Mètis à être multiple, fluide, et se jouer des aspects contraires qui mettent les forces en opposition. Zeus a incorporé Métis, le principe de la multiplicité qui lui confère une supériorité sur les autres. Comme tout métis, ne se tient-il pas à la croisée des destinées, des croyances, des savoirs, des points de vue ? Il jouit évidemment d'une ouverture sur la multiplicité qui lui ouvre les arcanes de la pensée complexe chère à Edgar Morin comme à Montaigne.

Or il est surprenant de constater combien dans la pensée moderne la Mètis a été suspectée et la personne métisse dévalorisée, diabolisée, combien elle a dérangé. Craint-on sa probable supériorité? Le fantasme de la modernité s'est appliqué principalement à séparer pour épurer. C'est le travail de dissociation visant à l'épuration qui a travaillé les mentalités. Que ce soit pour l'œuvre esthétique ou l'œuvre scientifique, la nouvelle quête du Graal passa par le processus de séparation, différenciation, épuration et désymbolisation. En même temps on écartait les poètes des sphères du savoir, on discréditait la portée cognitive de la métaphore et de l'analogie et on affirmait un positivisme à travers des logiques mentales visant au vrai. Ainsi naquirent les sciences modernes, sciences biologiques et sociales trouvant, qui dans la cellule, qui dans la psyché, qui dans le social, un objet scientifique précisément circonscrit (peut-être pas si précisément, car comme le disait Mauss : «c'est toujours aux frontières... »). 

logique de mouvements. Il cassa les conventions culturelles, les mises en scènes spatiales connotant une hiérarchie sociale, il ne voulut transmettre ni message, ni sentiment, ni valeur. Cet art minimal fut très intéressant en terme de capacité mentale à faire table rase. En effet cette désymbolisation des corps permit à la danse moderne de couper avec tout héritage (ou presque, car l'habitus, c'est ce qu'il y a d'inscrit au plus profond de l'inconscient, même chez Cunningham!). Le corps devenait alors disponible pour toute autre connotation ou métaphore: il pouvait entrer dans une problématique mathématique et fonctionner comme un signe algébrique, il était désexualisé rompant avec ces connotations surdéterminées d'être homme ou femme. Les danseurs étaient seulement corps, c'est-à-dire agencement de mouvements. d'ancêtres, mais finalement on n'a pas eu à choisir: la pensée moderne nous fit orphelins et ce statut nous rendit à la fois disponibles pour recommencer, mais aussi incultes grâce à l'école et aux médias, à la nouvelle disposition nucléaire de la famille, bref aux dispositifs organisationnels contemporains d'isolation ou d'individualisation. L'éducation physique est un bon exemple de cette instauration d'une rupture avec les savoirs passés, en coupant l'enfant de toutes les traditions corporelles jouées ou exprimées et de toutes les techniques du corps traditionnelles des cultures rurales et citadines d'antan (Denis D., 1999 ; Gaignebet C., 2002). Sans vouloir revisiter Foucault, il n'est qu'à le citer pour se rappeler que cela vaut pour toutes les institutions, notamment disciplinaires.

Or que peut-on faire quand on est sans tradition, sans héritage ? C'est le peintre Francis Bacon qui répond:

"Quand on est hors tradition comme tout artiste l'est aujourd'hui, on peut seulement chercher à rendre compte de ses propres sentiments vis- à- vis de certaines situations et selon son propre système nerveux » (Bacon F., 1976).

Et Jean Maisonneuve qui le cite, d'ajouter :

«Plus que jamais l'art est une sorte de " reportage ", d'exploration de l'intensité humaine » (Maisonneuve J., 1981 : 166).

La quête désespérée d'une vérité sur l'humain recule toujours les frontières de l'exploration du sujet, toujours plus isolé. Au regard des sensations de l'intérieur que Bacon choisit d'investiguer et de représenter, d'autres voies sont explorées, à l'opposé de l'intériorité : il s'agit d'amalgamer tout ce qui a fait sens, ailleurs, dans d'autres cultures, ou bien chez soi, avant, une manière d'être moi seul! D'où ce formidable mouvement de retour de balancier qui fait l'apologie de l'hétérogénéité que l'on veut postmoderne, de la relativité des points de vue dits scientifiques et du relativisme culturel. L'esprit New Age est celui d'un orphelin qui s'invente des parents, recompose sa filiation, choisit ses mythes. Du fond d'une forme de désespoir ou de nihilisme naît une recomposition qui puise abondamment dans les rituels des traditions qui existent de par le monde.

\section{Le métissage questionné, la désacralisation}

Il faut donc questionner cette vogue du métissage : afro-rythme, hip hop, capoeïra, salsa, reaggea, danses métisses sur tous les continents, et aussi sur le continent africain où des troupes de danse contemporaine mélangeant techniques occidentales et 
techniques traditionnelles se produisent dans des spectacles et des festivals, recyclage des traditions pour la grande mise en spectacle du monde. Donc métissage généralisé et attitude nouvelle revendiquée. Ce qu'il faut néanmoins questionner c'est comment les cultures qui ont gardé des liens profonds et vivants avec leurs racines, leurs ancêtres, leurs symboles, leurs totems viennent secourir des sociétés orphelines qui ont vécu la tabula rasa. Comment ce mouvement de métissage vient-il épauler les tentatives de réhabilitation des cultures anciennes ou populaires dans ses nouvelles restaurations patrimoniales ? Ce qu'il faut aussi questionner, mais dans l'autre sens, c'est comment la logique occidentale dominante impose sur tous les continents «l'économie politique occidentale du signe» dénoncée par Jean Baudrillard (1976), c'est-à-dire la transformation en marchandise potentielle de tous les sujets, les objets, les rituels. La planète étant parcourue en tous sens pour des déplacements incessants, transports des marchandises et de populations, il est assez «naturel » que le métissage soit devenu à la fois une mode récupérée par les arts, et une expérience quotidienne récupérée par la consommation de masse (culture monde). Sur le mode consommatoire, on assiste à des détournements des expressions symboliques locales. Cette forme de marchandisation à laquelle rien n'échappe, entre dans un processus qui dégrade le symbole en signe pour l'introduire dans la logique du marché d'échanges. Par exemple des clubs sportifs yankee et canadiens ont choisi comme mascottes des totems des tribus amérindiennes, les dessinant sur leurs tee-shirts, les vendant sous forme de peluche. Cette dégradation du Totem en logo sportif conduisit les Indiens à porter plainte finalement contre la récupération de leur divinité à des fins d'animation médiatique et commerciale. On peut comprendre le sentiment d'humiliation attenant à cette dégradation symbolique.

21 Mais la perte de l'aura symbolique est aussi actualisée par les acteurs mêmes des sociétés concernées. Aujourd'hui l'Afrique s'ouvre à l'esthétique occidentale et aménage des scènes théâtrales pour produire ses spectacles. De nombreuses compagnies de danse moderne chorégraphient des rituels africains pour entrer dans le circuit des festivals nationaux et internationaux. Non que ces rituels ne fussent pas utilisés de façon profane dans des fêtes traditionnelles en dehors du plan initiatique, mais ils étaient intégrés dans les célébrations traditionnelles. On peut dire que ces spectacles, dans leur contexte, nouaient les liens sociaux. Ce qui se développe actuellement en Afrique est différent et répond plus à l'esprit de la grande mise en spectacle des ressources patrimoniales pour des publics toujours plus variés et étrangers. Or ce procédé développe un comportement culturel particulier : la mise à distance de l'acteur et du public. Ce dispositif aiguise le regard critique de ce dernier, et l'engage à "payer pour voir». On a pu constater en Occident combien ce dispositif distend le lien social et fragilise la communauté en établissant des hiérarchies de goût, la fameuse distinction. L'institutionnalisation de cette séparation entre acteur et spectateur n'est pas anodine sur le plan anthropologique et ne peut être assimilée aux spectacles qui se donnaient en échange de quelques poulets ou autres cadeaux. Certes les acteurs transposaient des éléments du corpus "ritualistique», mais ceux-ci gardaient entière leur signification contextuelle, qui était comprise et partagée par les spectateurs. Aujourd'hui les éléments du rituel sont décontextualisés et perdent leur sens symbolique. Le sacré et le joyeux glissent dans le domaine de l'esthétique. Ce phénomène de la dégradation de l'expression du sacré et du pouvoir dans le culturel est la marque de toutes les mutations qui apparaissent avec les démocraties à l'occidentale, la séparation du spirituel et du politique. La danse aristocratique qui se donnait à la 
cour de Louis XIV pour « engager la diplomatie » s'est dégradée dans la danse-spectacle dès que les académies royales ont pris le relais de la formation des danseurs et de la production scénique (Bourcier P., 1978). Mais c'est aussi le même processus qui fut à l'œuvre dans la naissance des arts martiaux en Asie. Le Ju Do, et l'aïkido sont devenus des pratiques de loisir en quittant la dimension initiatique du pouvoir du samouraï, l'art du guerrier. C'est autour de l'Afrique de faire cette conversion et de décliner le sacré des rituels dans une forme commercialisée de produits culturels.

\section{Métissages : nouveaux repères, nouveaux imaginaires}

La transformation de la dimension sacrée, secrète et initiatique, donne accès au processus de métissage. Cela signifie d'abord que le contexte a changé et qu'un travail symbolique permet d'engager de nouveaux repères, de se réinscrire dans une nouvelle manière d'habiter le monde. Cela signifie donc qu'il y a eu d'abord une forme de perte des repères anciens par lesquels on appartenait à son monde. Le métissage n'est jamais un processus passif, ce n'est pas un simple amalgame, c'est une construction qui permet de continuer à donner du sens à sa vie.

Prenons l'exemple du hip hop qui débarque à Paris en provenance du Bronx et des boîtes new-yorkaises en 1982. Comment cette culture complexe, en gestation depuis longtemps dans les quartiers déshérités new-yorkais est immédiatement copiée et transformée par les Français des banlieues des grandes villes comme Paris, Lyon, Marseille? Comment les jeunes des banlieues ont-ils récupéré le hip hop américain comprenant tag, break dance et rap, expressions des marginalisés vivant en bandes et qui ont su canaliser dans des formes artistiques remarquables une violence endogène de leur lieu de vie? Les influences afro-américaines sont massives, mais aussi la culture du cartoon télévisuel, mais aussi le kung fu des films de bagarres, mais aussi le lookprison des noirs américains. A cela, il faut ajouter les emprunts particuliers qui différencient les styles.

Mais dans ce foisonnement étourdissant, on peut repérer dans la culture hip hop, dans la manière dont elle s'est instituée en France, quelques éléments singuliers du métissage culturel. Nous retiendrons deux traits saillants du métissage culturel dans la danse hip hop : celui qui engage une motricité unisexe et celui qui met les danseurs en dialogue avec le sol, avec la terre. Le hip hop renouvelle donc deux princeps structuraux de l'Occident: la différenciation incontournable homme/femme dérivant de l'amour courtois et l'inconscient ethnique relatif au rapport Tellus/Mater. C'est la première fois en Occident, depuis la Renaissance, que cette célébration de la terre apparaît dans la culture savante, c'est-à-dire au plus profond des motricités qui se donnent en spectacle sur des scènes subventionnées par l'Etat ${ }^{2}$. C'est là une réelle rupture, celle qui transforme l'intériorisation des gestes et des postures dans l'usage artistique du corps, et vient travailler l'inconscient collectif en rapport avec la représentation $\mathrm{du}$ "Tellus/Mater». Cette fonction métissante, confronte les Occidentaux à leur répulsion inconsciente de la terre, ce qui a fait leur spécificité dans le monde. L'Orient musulman ou bouddhiste, l'Afrique et l'Océanie ne connaissent pas cette répulsion orchestrée à la fin du Moyen Age par des réseaux d'Ordres religieux masculins parcourant l'Europe et réprimant la mentalité et les mœurs païennes (Michelet J., 1862) frappées d'obscurantisme. Derrière ce nouvel enjeu de pouvoir spirituel, une attitude de haine et de méfiance vis-à-vis du corps et de la chair, et 
notamment du corps féminin objet de tentation et de péché pour ces hommes de spiritualité chrétienne (Duby G., 1981) ${ }^{3}$, orchestra un nouvel imaginaire. Or, si la symbolique de nos tenues corporelles est depuis longtemps oubliée, elle vit néanmoins dans nos postures, nos réflexes, nos habitus et nos inconscients (plus ou moins conscients) collectifs et individuels. C'est ce refoulé que les jeunes issus de l'immigration ont fait surgir. Les techniques de danse du hip hop nous introduisent à des imaginaires africains qui font de la terre une référence technique et morale. Dans le hip hop il s'agit de sentir d'après les danseurs et les chorégraphes : «le centre de gravité de la terre", " d'avoir un toucher de la terre ", "de se sentir en complète harmonie avec le sol, épouser la terre ». L'Occident croyait avoir tout expérimenté en matière de mouvement, notamment avec les expérimentations postmodernes, mais il lui suffisait de changer d'imaginaire pour que s'impose une autre motricité. Celle que le hip hop offre, multiplie les liens avec le sol. Toutes les parties du corps peuvent entrer en contact avec le sol, l'épouser, le frotter ou le repousser, glisser... dans des mouvements ludiques, rythmiques, organisés autour de performances diverses : tourner sur des axes divers, axe épaule/hanche, axe vertical mais tours sur la tête, tours sur le dos, ou repoussés par le dos, le ventre, les mains, jeu de contacts à profusion qui prouve la recherche exaspérée du dialogue avec le sol et l'extrême plaisir qui y est pris. La danse moderne avait cru échapper à la motricité répulsive du sol en inventant les tours sur les genoux, ainsi que de nombreuses chutes au sol. Elle avait effectivement renouvelé le répertoire, mais la réelle révolution, l'inversion des ancrages inconscients appartient au hip hop. Evidemment, la valorisation de la terre élève le statut de la Mère dont l'Occident avait déprécié le rôle ${ }^{4}$. La vogue du hip hop, la valorisation de la fécondité comme en Afrique ont-elles une influence sur cette évolution des mentalités? La réponse est incertaine car il ne faudrait pas oublier l'usage commercial qui est fait de la valorisation de la consommatrice que constitue la femme enceinte.

Quoi qu'il en soit, l'art métis introduit à de nouveaux imaginaires, de nouvelles symboliques qui influencent les représentations collectives comme le souligne Jean-Luc Bonniol dans les paradoxes du métissage (2000). Le métissage culturel a aussi des rapports avec la façon philosophique d'envisager le monde et d'y inscrire sa trace. Une consultation du réseau Internet met en évidence que le terme de métissage est exclusivement utilisé pour des groupes de musique, de théâtre et de danse de la culture monde, cette nouvelle culture populaire qui s'échange entre les continents et que les expressions artistiques des courants alternatifs repèrent et intègrent en France. On trouve les sites faisant référence à l'afro-rythme, aux compagnies de hip hop (Magic electro, Aktuel force, Accrorap, Cie Tâ, Black Blanc Beur, Choréam etc.) où le métissage est la carte de visite, le mot de passe. On y trouve nombreux sites sur la capoeïra (do Brasil ou de France), et des théâtres d'avant-garde qui veulent renouveler le public «MAIF, CAMIF, Télérama». Une association de hip hop/ jazz s'est même appelée association Métissage "pour favoriser le mélange des cultures, des idées et des opinions, le mélange des styles", car c'est le mélange qui est productif. Cette manière de voir est commune à toutes ces associations qui agrègent des membres issus des anciennes colonies et d'autres qui font de la tolérance et de l'échange leur philosophie de vie. Il est intéressant de constater que cette démarche intellectuelle des populations venant principalement de l'immigration en France diffère complètement des postures des groupes ethniques aux Etats-Unis qui engagent leurs différences dans des conflits de bandes. 
26 En conclusion on pourrait dire que cette culture du métissage est une culture de l'ouverture et de la résistance qui émane d'un milieu populaire. Dans ce contexte de déconstruction de la pensée unidimensionnelle, les personnes ont pu travailler à définir une identité plus conforme à leur expérience. Certains et certaines ont entrevu la possibilité de définir un « Je » qui leur permette de résister aux conditions de leur vie quotidienne et trouver de quoi inventer d'autres références pour se situer dans un mouvement en devenir. Dans ces productions culturelles et artistiques une nouvelle «lutte pour la reconnaissance " pouvait s'opposer à ce que le sociologue allemand Axel Honneth appelle «le mépris de l'autrui généralisé » (1999). Ce mouvement interpelle aussi les dominants conduits à repenser leurs repères identitaires. Comment dire « Je », quand les cultures d'ailleurs viennent questionner la trame mentale du monothéisme patriarcal, cette référence centrale en train de s'effondrer. Michel Maffesoli parle d'une chute des références chrétiennes au profit d'un retour du polythéisme (2000), d'une socialité du ventre et des tribus. Il s'agirait d'une mutation profonde de notre civilisation.

La logique métisse s'affirme dans un nouveau bricolage humanoïde. Cette nouvelle voie consiste ou bien à mélanger de l'humain et de l'animal (en greffant un tissu épithélial humain sur une souris...), ou bien à incorporer des objets techniques en créant un homme/machine. Pour un artiste "performer" comme Stelarc qui invente des stratégies pour augmenter les possibilités de l'humain dans son environnement et les présente dans le monde entier à travers des événements artistiques, cela n'a plus de sens «de concevoir le corps comme un site pour la psyché ou le social». Le corps représente la fonction humaine de rendre compte du monde, or le corps n'est plus assez performant pour cela. Stelarc revendique le droit de modifier son ADN pour augmenter ses possibilités d'actions sur le monde et dans l'espace. L'idée postmoderne de faire de sa vie une œuvre d'art lui permet d'aller plus loin, car il reconnaît qu'il « se produit de la conscience » quand le corps fonctionne autrement ou «dysfonctionne». Ainsi a-t-il présenté des événements artistiques consistant à se suspendre à des crochets qui lui traversent l'épiderme. Cette expérience qui s'inspire de certains rituels initiatiques en usage dans des tribus indiennes avant qu'ils ne soient interdits par les colonisateurs oblige à restructurer sa perception du corps et de la conscience. A un autre niveau, Stelarc explore la conscience et le savoir du cybernaute, avec des implants multiples qui augmentent ses actions ou encore font de son corps une machine qui répond à des stimuli gérés par une décision extérieure, qu'elle soit volontaire ou aléatoire. Aussi s'est-il fait greffer un troisième bras articulé qui peut agir à travers des connexions complexes entre une machine et des contractions de ses muscles abdominaux. Là encore il développe une habileté qui brouille les repères entre la machine et l'homme, entre l'automatisme robotique et l'automatisme physiologique. Stelarc espère d'ailleurs qu'on se débarrassera au plus vite de la peau qui est une mauvaise interface entre l'environnement et la conscience et qu'il n'y aura plus ni intérieur ni extérieur, mais des montages, des réseaux, des circuits qui nous permettront de nous projeter dans le cosmos et d'étendre notre champ de perception et de connaissance. Stelarc pense d'ailleurs que nous allons à l'immortalité grâce à ces dispositifs de remplacement ou de rénovation. Ainsi le corps et le Moi peuvent-ils se dissocier, gain de liberté inestimable, «il s'agit d'une extrusion de la conscience " (1999 : 98).

Il serait maladroit de tenter une conclusion sur l'immense domaine des processus de métissages qui viennent toucher le corps et l'imaginaire au plus profond du social. 
Néanmoins une question émerge qui porte sur la capacité humaine à s'adapter à la complexité, à s'ouvrir à l'étrange de l'étranger tout en gardant sa "verticalité " (Pradier J.-M.,1997). Le métissage n'est pas n'importe quoi dans un monde chaotique en déficit de références éthiques. On peut craindre la simplification qui consiste, après avoir travaillé la névrose épurative propre aux monothéismes et aux sciences positivistes, à tomber dans un autre dérèglement systématique. Faire de l'amalgame une nouvelle voie de marchandisation des objets et des personnes. Les technologies à la réputation de « dures » comme la cybernétique, la génétique, l'intelligence artificielle... ont compris la puissance de l'hybridation. Peut-on parler de retournement ou d'avatar de la pensée métisse ? La logique du métissage qui faisait l'art mineur et les délices du partage et du mélange (Laplantine F., Nouss A., 1997) est en train de devenir une logique nouvellement dominante dans certains cercles, hier positivistes. L'intelligence de la Métis saura-t-elle triompher de ce nouveau retournement de situations?

\section{BIBLIOGRAPHIE}

Denis D. (1997) Conférence, Colloque Comment peut-on enseigner une culture corporelle? Montpellier, 29, 30, 31 mai.

Bacon F. (1976) L'Art de l'impossible (entretiens avec D. Sylvester), Genève, SIRKA.

Baudrillard J. (1976) L'Echange symbolique et la mort, Paris, Gallimard.

Bonniol J.-L (2000) Les Paradoxes du métissage, Paris, Coll. CTSH.

Bourcier P. (1978) Histoire de la danse en Occident, Paris, Seuil, Point.

Detienne M., Vernant J.-P. (1974) Les Ruses de l'intelligence. La mètis des Grecs, Paris Flammarion.

Duby G. (1981) Le Chevalier, la femme et le prêtre, Paris, Hachette.

Ellenberger H.F.(1970) The Discovery of the Unconscious. The history and evolution of dynamic psychiatry, trad. Histoire de la découverte de l'inconscient, Paris, Fayard (1994).

Gaignebert C. (2002) Le Folklore obscène des enfants, MNR.

Gruzinski S. (1999) La Pensée métisse, Paris, Fayard.

Honneth A. (2000) La Lutte pour la reconnaissance, Paris, Cerf.

Laplantine F., Nouss A. (1997) Le Métissage, Paris, Flammarion.

Latour B. (1991) Nous n'avons jamais été modernes. Essai d'anthropologie symétrique, Paris, La Découverte.

Maffesoli M. (1979) La Conquête du présent, Paris, PUF.

Maffesoli M. (2000) Terre - Mère : Gaïa, in Cultures en mouvement (« Sexualités »), 24, 11.

Maisonneuve J., Bruchon-Schweitzer M. (1981) Modèles du corps et psychologie esthétique, Paris, P.U.F.

Mauss M. (1950) Sociologie et anthropologie, Paris, PUF. 
Michelet J. (1862) La Sorcière, Paris, réed 1966.

Midol N. (2000) Métissage culturel et construction identitaire : l'exemple du Rap, in Faire justice aux adolescents, Cultures en mouvement, 26.

Midol, N. (1995) Démiurgie dans les sports et la danse, Paris, L'Harmattan, (col. Santé, sociétés et cultures).

Midol, N. (1986) Le Jazz, de la tradition à la modernité Paris, Amphora.

Midol, N. (1981) Théorie et pratique de la danse moderne, Paris, Amphora.

Midol, N., Pissard, H. (1984) La Danse jazz : de la tradition à la modernité, Paris, Amphora.

Pradier J.-M. (1997) La Scène et la fabrique des corps, Bordeaux, PUB.

Serres M. (1985) Les Cinq sens : philosophie des corps mêlés, Paris, Grasset.

Stelarc (1999) Vers le post-humain, Nouvelles de danse, 36/37, 9, 80-98.

Vernant J.-P. (1999) L'Univers, les dieux, les hommes, Paris, Seuil.

Virno P. (1991) Opportunisme, Cynisme et peur. Ambivalence du désenchantement, Cahors, L'Eclat.

\section{RÉSUMÉS}

Comment des cultures se mélangent-elles, dans quelles circonstances et selon quelles modalités? La mise en contact de deux cultures peut engager un phénomène de métissage dont on cherchera les niveaux de créativité. Le métissage vient-il jusqu'au niveau corporel modifier, non seulement des techniques artisanales mais aussi des techniques du corps ? Les exemples pris dans la danse moderne américaine à l'époque du Denishawn ou dans le mouvement du hip hop, ou encore dans la danse moderne en Afrique sont autant d'exemples de métissage qui concernent tout autant les façons de penser que celles de bouger son corps.Et maintenant il reste à questionner le métissage homme/machine chez le » cyborg ».

How Cultures invent interactions which produce half-caste of persons? And what is the level of creativity appearing in-between two ethnic cultures ? Certainly mind is changing, but also body movement, action, and esthetic performance. Any example are finding on modern dance at Denishawn School, or hip hop, or Modern African Dance give answers. And now we have to question the relationship between body and machine through the cyborg type.

\section{INDEX}

Mots-clés : imaginaire, danse, métissage, mythologie

Keywords : imaginary, dance, cultural half-breeding, mythology

\section{AUTEUR}

\section{NANCY MIDOL}

LAMIC, Laboratoire d'Anthropologie « Forme du partage, mémoire, identité, cognition sociale », UNSA, Université de Nice 